University of Nebraska - Lincoln

DigitalCommons@University of Nebraska - Lincoln

2010

\title{
Demographic and Clinical Variation in Veterans Health Administration Provision of Assistive Technology Devices to Veterans Poststroke
}

\author{
Sandra L. Hubbard Winkler \\ Veterans Health System \\ Diane C. Cowper Ripley \\ Veterans Health System \\ Samuel Wu \\ Veterans Health System \\ Dean M. Reker \\ Edward Hines Jr Veterans Affairs Medical Center \\ Bruce Vogel \\ Veterans Health System \\ See next page for additional authors \\ Follow this and additional works at: https://digitalcommons.unl.edu/publichealthresources \\ Part of the Public Health Commons
}

Hubbard Winkler, Sandra L.; Cowper Ripley, Diane C.; Wu, Samuel; Reker, Dean M.; Vogel, Bruce; Fitzgerald, Shirley G.; Mann, William C.; and Hoenig, Helen, "Demographic and Clinical Variation in Veterans Health Administration Provision of Assistive Technology Devices to Veterans Poststroke" (2010). Public Health Resources. 201.

https://digitalcommons.unl.edu/publichealthresources/201

This Article is brought to you for free and open access by the Public Health Resources at DigitalCommons@University of Nebraska - Lincoln. It has been accepted for inclusion in Public Health Resources by an authorized administrator of DigitalCommons@University of Nebraska - Lincoln. 


\section{Authors}

Sandra L. Hubbard Winkler, Diane C. Cowper Ripley, Samuel Wu, Dean M. Reker, Bruce Vogel, Shirley G.

Fitzgerald, William C. Mann, and Helen Hoenig 


\title{
Demographic and Clinical Variation in Veterans Health Administration Provision of Assistive Technology Devices to Veterans Poststroke
}

\author{
Sandra L. Hubbard Winkler, PhD, OTR, Diane C. Cowper Ripley, PhD, Samuel Wu, PhD, \\ Dean M. Reker, PhD, RN, Bruce Vogel, PhD, Shirley G. Fitzgerald, PhD, William C. Mann, PhD, \\ Helen Hoenig, MD
}

ABSTRACT. Hubbard Winkler SL, Cowper Ripley DC, Wu S, Reker DM, Vogel B, Fitzgerald SG, Mann WC, Hoenig H. Demographic and clinical variation in Veterans Health Administration provision of assistive technology devices to veterans poststroke. Arch Phys Med Rehabil 2010;91:369-77.

Objectives: To examine variation in provision of assistive technology (AT) devices and the extent to which such variation may be explained by patient characteristics or Veterans Health Administration (VHA) administrative region.

Design: Retrospective population-based study.

Setting: VHA.

Participants: Veterans poststroke in fiscal years 2001 and $2002(\mathrm{~N}=12,046)$.

Interventions: Not applicable.

Main Outcome Measure: Provision of 8 categories of AT devices.

Results: There was considerable regional variation in provision of AT. For example, differences across administrative regions in the VHA ranged from 5.1 to 28.1 standard manual wheelchairs per 100 veterans poststroke. Using logistic regression, with only demographic variables as predictors of standard manual wheelchair provision, the $c$ statistic was .62 , and the pseudo $R^{2}$ was $2.5 \%$. Adding disease severity increased the $c$ statistic to .67 and the pseudo $R^{2}$ to $6.2 \%$, and adding Veteran Integrated Network System further increased the $c$ statistic to .72 and pseudo $R^{2}$ to $9.8 \%$.

Conclusions: Our research showed significant variation in the provision of AT devices to veterans poststroke, and it showed that patient characteristics accounted for only $6.2 \%$ of the variation. VHA administrative region and disability severity accounted for equivalent amounts of the variation.

From the Rehabilitation Outcomes Research Center Research Enhancement Award Program, North Florida/South Georgia Veterans Health System, Gainesville, FL (Hubbard Winkler, Cowper Riley, Wu, Vogel); Department of Occupational Therapy, College of Public Health and Health Professions (Hubbard Winkler, Mann), and Department of Epidemiology and Health Policy Research, College of Medicine (Cowper Riley, Wu, Vogel), University of Florida, Gainesville, FL; Edward Hines Jr Veterans Affairs Medical Center, Hines, IL (Reker); James A. Haley Medical Center, Tampa, FL (Fitzgerald); Durham Veterans Affairs Medical Center, Durham, NC (Hoenig); Department of Medicine, Duke University, Durham, NC (Hoenig).

Supported by the Veterans Affairs (VA) HSR\&D/RR\&D Rehabilitation Outcomes Research Center and a VA Rehabilitation Research and Development Award (grant no. F3736R).

The findings and views in this article are those of the authors and do not necessarily represent those of the Veterans Administration.

No commercial party having a direct financial interest in the results of the research supporting this article has or will confer a benefit on the authors or on any organization with which the authors are associated.

Reprints requests to Sandra L Hubbard Winkler, PhD, OTR/L, ATP, North Florida/ South Georgia Veterans Health System, 1601 SW Archer Rd (151B), Gainesville, FL

32608-1197, e-mail: Sandra.Hubbardl@va.gov, shubbard@phhp.uf.edu.

0003-9993/10/9103-00821\$36.00/0

doi:10.1016/j.apmr.2009.10.028
Our findings suggest the need for improvements in the process for providing AT and/or provider education concerning device provision.

Key Words: Rehabilitation; Wheelchairs.

Published by Elsevier Inc on behalf of the American Congress of Rehabilitation Medicine.

NVESTIGATORS STUDYING health care use (the amount or pattern of usage of health care services) have found variations in provision of health care services that were poorly explained by the clinical characteristics. ${ }^{1,2}$ In particular, small area variations research examines geographical variations in health care, and it has led to important advances in the way clinical services are provided. ${ }^{3}$ The field of assistive technology has great potential to benefit from such research. There is marked variation in the costs of wheeled mobility devices, with retail values ranging from around $\$ 300$ for a basic manual wheelchair ${ }^{4}$ to over $\$ 3000$ for an ultra-lightweight wheelchair, ${ }^{5}$ while a specialized power wheelchair can cost upwards of $\$ 29,000$. $^{6}$ Advances in technology in recent years have brought highly dynamic prescribing practices for wheeled mobility devices. The number of Medicare beneficiaries seeking reimbursement for power wheelchairs increased $189 \%$ over 4 years (while the overall Medicare population rose only $1 \%$ a year during that same period) ${ }^{7}$ and the VA experienced an increase of $103 \%$ over 3 years. ${ }^{8}$ There is geographic variation in provision of wheelchairs and scooters provided by the VHA, suggesting that some facilities may be overprescribing and others may be underprescribing these devices. ${ }^{9}$ Similar geographic variation has been found in the provision of wheeled mobility devices by Medicare. ${ }^{10}$ Little is known about the factors underlying variation in provision of assistive technology devices.

Few studies have examined assistive device provision as opposed to device use. Both are important, but studying device provision is most critical for cost-containment and health care policy. Rather than asking who is using the technology, in this study and our prior studies, we ask if veterans receive the same type/quality of technology across the VHA national system of care. In an earlier study, we found minority subjects were more likely to receive manual wheelchairs and white subjects more

List of Abbreviations

$\begin{array}{ll}\text { ADLs } & \text { activities of daily living } \\ \text { FRG } & \text { Function Related Groups } \\ \text { VA } & \text { Veterans Affairs } \\ \text { VAMC } & \text { Veterans Affairs Medical Center } \\ \text { VHA } & \text { Veterans Health Administration } \\ \text { VISN } & \text { Veteran Integrated Network System }\end{array}$




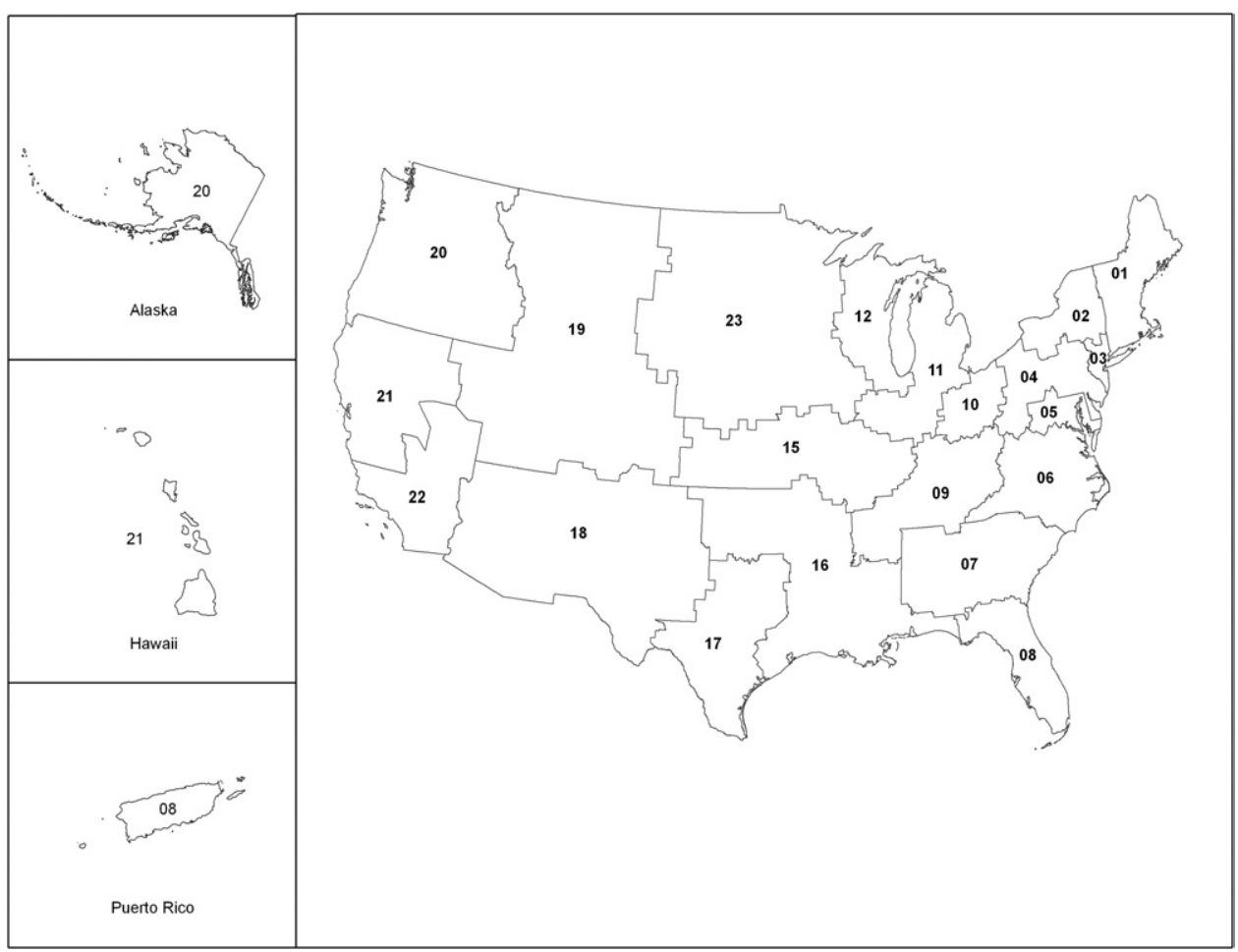

Fig 1. Map of VISNs.

likely to receive power wheelchairs and scooters. ${ }^{8}$ Diagnosis also was a significant predictor of the type of wheelchairs and scooters provided. ${ }^{8,11}$ Need for a wheelchair clearly can vary with diagnosis and with severity of illness, both of which also can vary with race, ${ }^{12,13}$ and there are well known differences in demographic characteristics across geographic regions in the United States. Administratively, the VHA has organized the approximately 1127 VHA facilities into 21 administrative regions called VISNs (fig 1), which allow for study of regional variations in health care delivery. Thus, a logical next step was to determine whether severity of disability within a single diagnosis or VHA administrative region accounted for the variability in provision of assistive devices to veterans.

We carried out a retrospective study of a cohort of veterans who received care for a first stroke in the VHA during FY01-02 to answer 2 research questions: (1) Does provision of specific types of assistive devices to veterans poststroke vary by VHA administrative region? (2) Are demographic characteristics, clinical characteristics, or VHA administrative region associated with the provision of specific types of assistive devices?

\section{METHODS}

\section{Study Design}

This was a retrospective population-based cohort study. The project was approved by the Kansas City VAMC, the VAMC Pittsburgh, and the University of Florida/North Florida/South Georgia Veterans Healthcare Systems Institutional Review Boards (Human Subjects Subcommittees of the Research and Development Committee).

\section{Study Sample}

Two national VA databases were used to identify the cohort: the Integrated Stroke Outcomes Database ${ }^{14}$ and the Medical $\mathrm{SAS}^{\mathrm{a}}$ datasets. The Integrated Stroke Outcomes Database includes clinical and administrative data on a nationwide cohort of patients who have been identified by VHA clinicians as having a new stroke and who have been evaluated using the FIM recorded in the Functional Status Outcomes Database. ${ }^{15}$ The Medical SAS datasets, generated from the National Patient Care Database and housed at the Austin Information Technology Center, ${ }^{16}$ receive daily encounter data from VHA clinical information systems including demographic information, the date and time of service, the practitioners who provided the service, the location where the service was provided, diagnoses, and procedures. To augment the Integrated Stroke Outcomes Database and ensure we captured all stroke cases in the VHA during FY01-02, we applied a high-specificity algorithm developed and validated by investigators in a prior study ${ }^{17}$ to the VHA Patient Treatment File main inpatient episodes of care. The algorithm selected stroke patients using primary and secondary International Classification of Diseases-9th Revision diagnosis codes. The inclusion criterion was a first stroke during FY 01-02 in the Integrated Stroke Outcomes Database and/or VHA Patient Treatment File. There were no exclusion criteria.

Once the study cohort was identified, a file of unique identifiers (1 per veteran) was created using scrambled Social Security number. This file was used to collect existing data from multiple other electronic information sources to complete the study data set. Inpatient and outpatient use information and diagnosis codes for comorbidity measurement were obtained from VA Medical SAS database. Assistive technology data for 
3 fiscal years (FY01-FY03) were obtained from the National Prosthetic Patient Database, housed at the VA Central Office National Prosthetics and Sensory Aids Services for all veterans in the study cohort.

\section{Operational Definitions}

Outcome (dependent) variables. Categorization of assistive devices for this study was based on previous categorization of wheelchairs and scooters using Healthcare Common Procedure Codes, ${ }^{8,9}$ developed through review of the literature, ${ }^{18-22}$ as applied to all assistive devices provided by the VHA that are included in the National Prosthetic Patient Database. The resulting categories were (1) standard manual, or depot, wheelchairs; (2) hemi and lightweight rehabilitation manual wheelchairs; (3) ultralight manual wheelchairs; (4) power wheelchairs; (5) scooters; (6) orthotics, including ankle foot orthotics and knee foot orthotics; (7) walkers, crutches, and canes; (8) beds; (9) patient lifts; (10) devices for self care with ADLs (bathing, toileting, grooming, and feeding, such as raised toilet seats, toilet seats with rails, tub benches, adapted utensils, and so forth); and (11) wheelchair lifts and ramps. For each of these categories, our primary analyses compare persons who received 1 or more devices with those who received no device.

\section{Independent Variables}

VHA administrative region. The 1995 Plan to Restructure the VHA organized the approximately 1127 VHA facilities into 21 administrative regions, or VISNs, based on geographic proximity and long-standing clinical relationships (see fig 1). A VISN may include more than 1 state (eg, in New England), and large states (eg, Texas) may be in more than 1 VISN. The referent VISN for each logistic regression was determined as follows: the mean number of devices provided per veteran by each VISN was calculated for each of the 11 categories of devices. The median VISN, according to the number of devices per veteran for each VISN, became the referent VISN for that particular device.

Severity of disability. The FIM-FRG system ${ }^{23-26}$ was used to control for severity of disability. The FIM-FRG system is a case-mix adjustment methodology that classifies patients at the time of admission to facilitate prediction of length of stay and functional outcomes. The FIM-FRG system allows comparison of outcomes across impairment groups and levels of functional severity. ${ }^{24}$ Figure 2 shows the 9 FRGs and the percentage of veter-

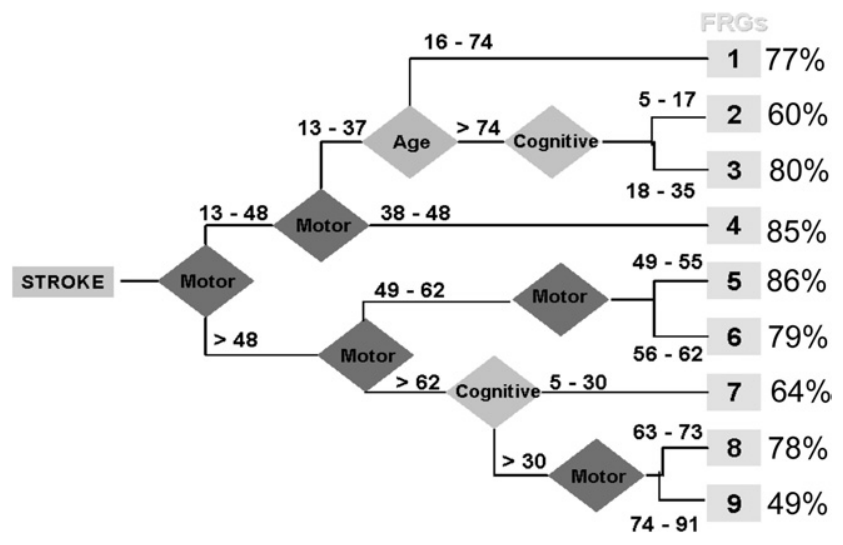

Fig 2. How FIM motor and cognitive scores and age of subjects poststroke are used to derive the 9 FRG categories. The last column shows the percentage of veterans in this study who received assistive devices per FRG category. ans in this study who received assistive devices per FIM-FRG group.

Demographic characteristics. Demographics for veteranrelated independent variables were taken from the National Patient Care Database data as follows:

- Age: calculated by subtracting date of birth from the index stroke admission date

- Sex: male, yes/no

- Marital status: married, yes/no

- Race/ethnicity: defined according to the 6 National Patient Care Database race categories of Hispanic black, Hispanic white, American Indian, African American, Asian, and Caucasian; Caucasian was the referent for logistic regression analyses

- Service connection status: service-connected, yes/no

Rehabilitation. The rehabilitation variable, from the Integrated Stroke Outcomes Database, denotes whether the veteran received specialized in-patient rehabilitation services in an acute or subacute rehabilitation bedservice unit with dedicated beds.

Nursing home admission. The nursing home admission variable, from the Integrated Stroke Outcomes Database, denotes whether the veteran was admitted for treatment of their index stroke from a nursing home.

\section{Analyses}

To answer research question 1 , "Does provision of specific types of assistive devices to veterans with stroke vary by VHA administrative region? (ie, VISN)?" we calculated the mean number of devices per veteran by VHA administrative region (VISN) and the proportion of veterans who were provided devices, per device category, within each VISN. $z$ Scores and their corresponding $P$ values were used to determine whether provision at the VISN level was significantly different from provision at the national level, per device category. To correct for multiple device categories, statistical significance was determined based on the Hochberg ${ }^{27}$ step-up procedure. Using Geographic Information Systems tools, 1 map was created for each device category to show the provision of device by VISN.

To address research question 2, "Are demographic, clinical characteristics, or VHA administrative region (VISN) associated with provision of devices?" we performed bivariate comparisons followed by multivariate logistic regression. Bivariate tests compared veterans who received and did not receive assistive devices for each of the demographic and clinical characteristics, using $t$ tests for comparison of mean values and chi-square test for categorical comparisons. We used logistic regression for the multivariate regressions based on work by Biddiss and Chau, ${ }^{28}$ who compared 3 multivariate methods (logistic regression, neural net, decision tree approaches) to examine prosthetic device use. They found similar results with linear and nonlinear methods (logistic regression and neural net, respectively) for overall accuracy, and they noted that the results with logistic regression are more easily interpreted and more widely accepted. Three logistic regression models were fitted and run for 8 of the 11 device categories. Logistic regression models predicting the any versus no provision of a device were not carried out for the following devices: (1) devices used for ADLs, because all veterans received at least 1 such device (mean \pm SD, 1.4 \pm 0.3 ); (2) wheelchair lifts, because of the strong correlation between wheelchairs and wheelchair lifts; and (3) ultralight manual wheelchairs, because very few ultralight manual wheelchairs were provided (62 such wheelchairs provided across the entire nation). For the 3 sequential regression models, the outcome variable was any versus no provision of device. For model 1, the predictor 
Table 1: Demographic and Clinical Characteristics

\begin{tabular}{|c|c|c|c|}
\hline Variable & Cohort & $\begin{array}{l}\text { Received } \\
\text { Device } \\
\text { From VHA }\end{array}$ & $\begin{array}{c}\text { Received } \\
\text { no Device } \\
\text { From VHA }\end{array}$ \\
\hline No. of unique veterans & $12,046(100)$ & $4842(40)$ & $7204(60)$ \\
\hline \multicolumn{4}{|l|}{ Sex } \\
\hline Male & $11,799(98)$ & 4745 (98) & 7054 (98) \\
\hline Female & $247(2)$ & $97(2)$ & $150(2)$ \\
\hline Missing & & 0 & \\
\hline \multicolumn{4}{|l|}{ Race } \\
\hline Hispanic, white & $919(8)$ & $295(6)$ & $624(9)$ \\
\hline Hispanic, black & $77(<1)$ & $28(<1)$ & $49(<1)$ \\
\hline American Indian & $48(<1)$ & $12(<1)$ & $36(<1)$ \\
\hline Black & $2602(22)$ & $988(21)$ & $1604(22)$ \\
\hline Asian & $53(<1)$ & $17(<1)$ & $36(<1)$ \\
\hline White & $9243(69)$ & $3417(72)$ & $4826(67)$ \\
\hline Missing & 104 & 75 & 29 \\
\hline Age $(y)$, mean $\pm S D$ & $68 \pm 11$ & $69 \pm 11$ & $68 \pm 12$ \\
\hline Missing & & 0 & \\
\hline \multicolumn{4}{|l|}{ Service-connected } \\
\hline Yes & $3329(28)$ & $1218(25)$ & $2111(29)$ \\
\hline No & $8717(72)$ & $3624(75)$ & $5093(71)$ \\
\hline Missing & & 30 & \\
\hline \multicolumn{4}{|l|}{ Married } \\
\hline Yes & $6055(51)$ & $2229(46)$ & $3694(52)$ \\
\hline No & $5923(49)$ & $2583(54)$ & $3472(48)$ \\
\hline Unknown or missing & 68 & 30 & 38 \\
\hline \multicolumn{4}{|l|}{ Severity of disability } \\
\hline FRG 1 & 1224 & $947(77)$ & $277(23)$ \\
\hline FRG 2 & 540 & $326(60)$ & $214(40)$ \\
\hline FRG 3 & 335 & $268(80)$ & $67(20)$ \\
\hline FRG 4 & 663 & $563(85)$ & $100(15)$ \\
\hline FRG 5 & 492 & $422(86)$ & 70 (14) \\
\hline FRG 6 & 524 & $414(79)$ & $110(21)$ \\
\hline FRG 7 & 619 & $399(64)$ & $220(36)$ \\
\hline FRG 8 & 334 & $262(78)$ & $72(22)$ \\
\hline FRG 9 & 705 & $345(49)$ & $360(51)$ \\
\hline Missing & & 6610 & \\
\hline
\end{tabular}

$\overline{\text { NOTE. Values are numbers and percentages unless otherwise indicated. }}$

variables included only demographic and clinical characteristics-that is, age, sex, service connection, marital status, race/ ethnicity, and whether the veteran received inpatient rehabili- tation. Model 2 included severity of disability (FIM-FRG) in addition to variables in model 1 . Model 3 was the same as model 2 except VHA administrative region (VISN) was added. Two covariates were included in all models: whether the veteran was admitted from a nursing home and whether the veteran died; these variables were included to account for severity of illness. SAS version $8.2^{\mathrm{a}}$ was used for all analyses.

\section{RESULTS}

Table 1 characterizes the entire population-based cohort of this study (veterans hospitalized in the VHA for stroke during FY01-FY02) and compares veterans who received devices from the VHA only with veterans who did not receive any assistive devices, according to demographic and clinical characteristics. These exploratory, bivariate analyses showed that race, age, marital status, service connection, and stroke severity each were significantly $(P<.001)$ related to device provision, but sex was not. Although statistically significant, the actual differences in device provision according to demographic characteristics were relatively small. For example, 69\% of the overall veteran population was white, and $72 \%$ of those receiving devices were white, whereas, $22 \%$ of the overall veteran population was black, and $21 \%$ of those receiving devices were black-differences of only $1 \%$ to $3 \%$. In contrast, the differences in device provision according to FIM-FRG were statistically significant, and they were large. For example, $85 \%$ of persons with moderate disability (FIM-FRG 4) received 1 or more devices, compared with less than $50 \%$ of persons with the lowest category of disability (FIM-FRG 9). The greatest proportions of veterans receiving assistive devices were in FIMFRG 4 and FIM-FRG 5, followed by veterans in FIM-FRG 3, FIM-FRG 6, FIM-FRG 8, and FIM-FRG 1.

Table 2 shows descriptive data on provision of the various categories of devices. Diverse mobility devices were provided, ranging from .65 canes/walkers/crutches per veteran poststroke to .02 power wheelchairs per veteran (ie, 65 of every 100 veterans poststroke received a gait aid, but only 2 in 100 veterans got a power wheelchair). Veterans poststroke received a mean of 1.4 ADL devices with a SD of 0.3 . Within ADL devices, reachers, long-handled bath sponges and shoe horns, and sock aids and dressing sticks, respectively, were the most frequent dressing, grooming, and kitchen aid devices provided, respectively; the most frequent bathroom devices were tub benches, shower chairs, grab bars, raised toilet seats, and toilet rails (supplemental fig 3).

Table 2: Mean Number of Devices Provided per Veteran With SD and Scale for Mappings in Figure 3 in Devices per 100 Veterans for Each Category of Device

\begin{tabular}{|c|c|c|c|c|}
\hline \multirow[b]{3}{*}{ Device } & \multirow[b]{3}{*}{ Mean $\pm S D$} & \multicolumn{3}{|c|}{ Devices per 100 Veterans } \\
\hline & & \multicolumn{3}{|c|}{ Quartiles } \\
\hline & & Lower $25 \%$ & Middle $50 \%$ & Upper $25 \%$ \\
\hline AFO/KFO & $0.14 \pm 0.48$ & $4.5-6.8$ & $6.9-10.8$ & $10.9-17.1$ \\
\hline Walker/cane/crutch & $0.65 \pm 0.08$ & $48.5-59.4$ & $59.5-69.5$ & $69.6-76.7$ \\
\hline Beds & $0.13 \pm 0.04$ & $6.5-8.6$ & $8.7-16.5$ & $16.6-22.6$ \\
\hline Patient lifts & $0.05 \pm 0.03$ & $1.6-3.1$ & $3.2-6.2$ & $6.3-12.2$ \\
\hline Standard manual wheelchair & $0.17 \pm 0.07$ & $5.1-13.3$ & $13.4-22.4$ & $22.5-28.1$ \\
\hline Hemi/lightweight manual wheelchair & $0.09 \pm 0.03$ & $4.5-6.9$ & 7.0-10.9 & $11.0-12.6$ \\
\hline Power wheelchair & $0.02 \pm 0.01$ & $0-1.0$ & $1.1-2.3$ & 2.4-3.9 \\
\hline Scooter & $0.02 \pm 0.01$ & $0.3-1.1$ & $1.2-2.8$ & $2.9-4.7$ \\
\hline ADL (mapping appendix only) & $1.42 \pm 0.33$ & $0.7-1.2$ & $1.3-1.5$ & $1.6-2.1$ \\
\hline Total devices per veteran (mapping not shown) & $2.71 \pm 0.46$ & $1.6-2.5$ & $2.6-2.9$ & $3.0-3.6$ \\
\hline
\end{tabular}

Abbreviations: AFO, ankle foot orthotic; KFO, knee foot orthotic. 

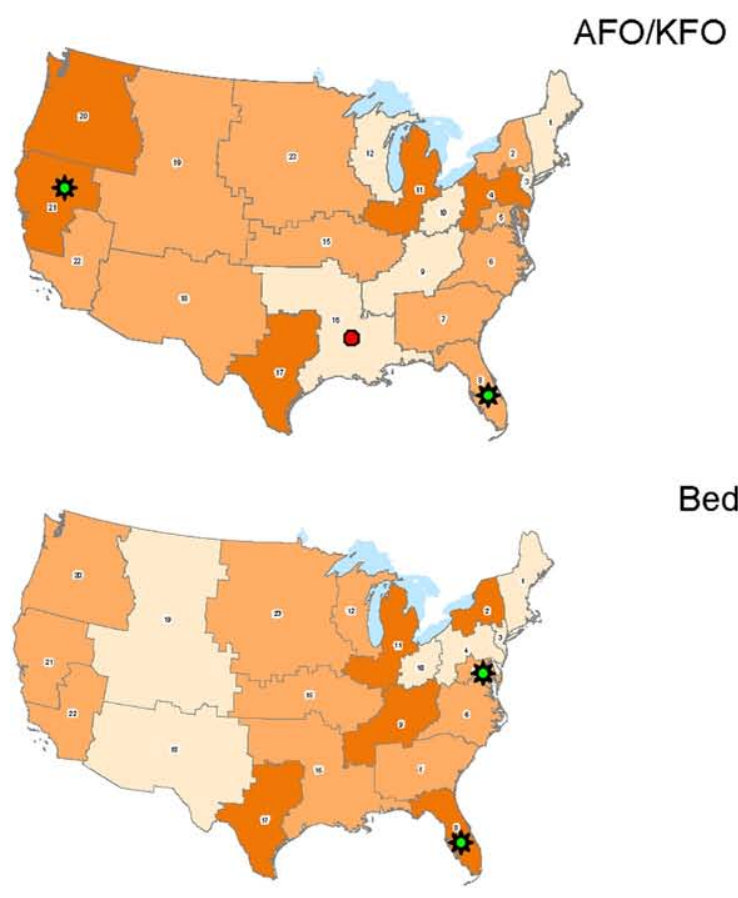

Beds
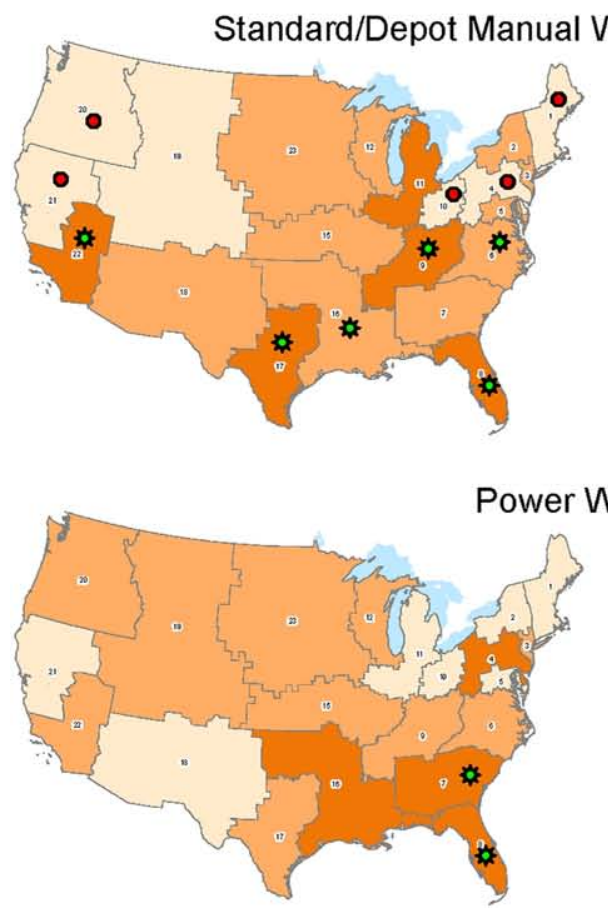
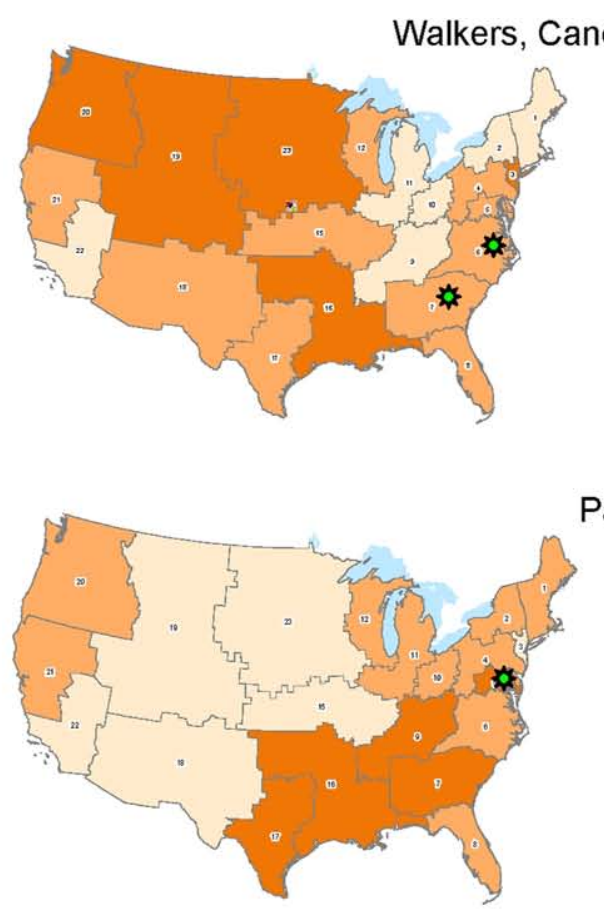

Patient Lifts
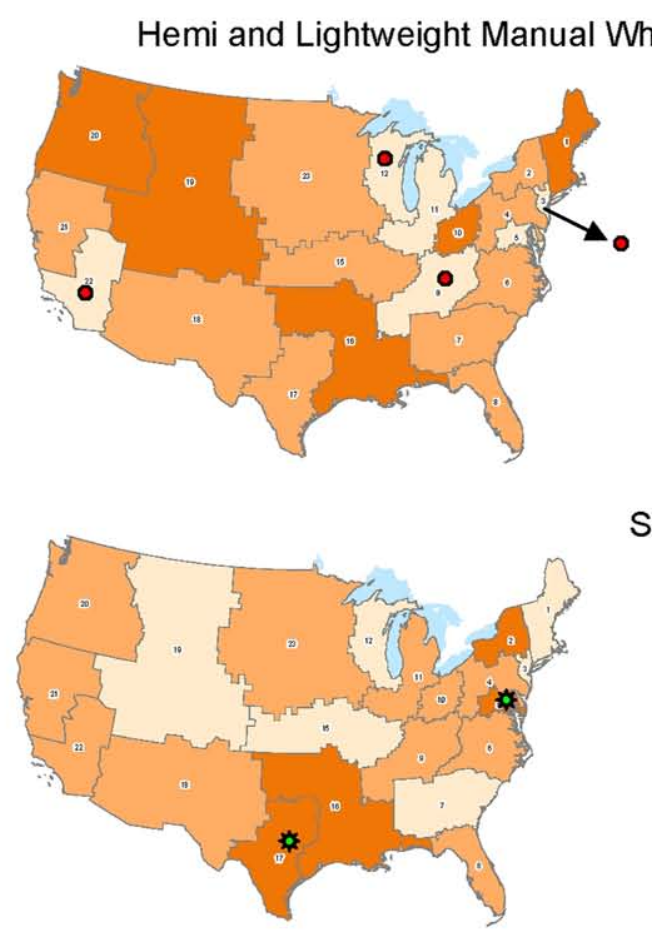

\section{Scooter}

Fig 3. Shading indicates use patterns by quartile, per VISN, per device. Light shading, $0 \%$ to $25 \%$ quartile; medium shading, $25 \%$ to $75 \%$ quartiles; dark shading, $75 \%$ to $100 \%$ quartile. Symbols indicate VISNs with use patterns significantly different than the national mean after adjusting for demographic and severity of disability factors. Star indicates significantly more devices; octagon indicates fewer devices. Abbreviations: AFO, ankle foot orthotic; KFO, knee foot orthotic.

Figure 3 is a mapping that shows the provision pattern $(z$ score results) of 8 of the 11 AT device categories (the device categories on which we also did multivariate modeling; information on all devices available on request from the authors). The maps show the VHA regions (VISNs) that were in the upper $25 \%$, middle $50 \%$, and lower $25 \%$ quartiles for provision of devices per 100 veterans (see table 3 for specific values pertaining to the various quartiles for each device). The shading in figure 3 shows the quartiles from $z$ score analyses (research question 1). The symbols 
Table 3: Significant Logistic Regression Results for Standard Manual/Depot Wheelchairs

\begin{tabular}{|c|c|c|c|c|c|c|}
\hline \multirow{3}{*}{$\begin{array}{l}\text { Pseudo } R^{2} \\
c \text { Statistic }\end{array}$} & \multicolumn{2}{|c|}{$\begin{array}{c}\text { Model } 1 \\
\text { Demo Only } \\
\text { No. Used }=11,978 \\
\text { Depot }=\text { Yes, No. }=2063\end{array}$} & \multicolumn{2}{|c|}{$\begin{array}{c}\text { Model } 2 \\
\text { Demo }+ \text { FRG } \\
\text { No. Used }=5489 \\
\text { Depot }=\text { Yes, No. }=1220\end{array}$} & \multicolumn{2}{|c|}{$\begin{array}{c}\text { Model } 3 \\
\text { Demo }+ \text { FRG }+ \text { VISN } \\
\text { No. Used }=5489 \\
\text { Depot }=\text { Yes, No. }=1220\end{array}$} \\
\hline & .025 & & .062 & & .098 & \\
\hline & .620 & & .670 & & .716 & \\
\hline & OR & $\mathrm{Cl}$ & OR & $\mathrm{Cl}$ & OR & $\mathrm{Cl}$ \\
\hline \multicolumn{7}{|l|}{ IV } \\
\hline Age & 1.01 & $1.01-1.02$ & & & \multicolumn{2}{|c|}{ NS } \\
\hline Hispanic & 1.65 & $1.41-1.94$ & 1.57 & $1.24-1.99$ & & \\
\hline Black & 1.27 & $1.13-1.43$ & 1.22 & $1.04-1.43$ & & \\
\hline Service-connected & 1.23 & $1.11-1.37$ & 1.18 & $1.02-1.36$ & & \\
\hline Rehabilitation & 2.01 & $1.77-2.29$ & 1.28 & $1.11-1.48$ & 1.21 & $1.03-1.42$ \\
\hline $\operatorname{frg} 1$ & & & 4.30 & $3.26-5.69$ & 4.61 & $3.47-6.13$ \\
\hline frg2 & & & 3.65 & $2.59-5.13$ & 3.77 & $2.66-5.34$ \\
\hline frg3 & & & 4.91 & $3.44-7.01$ & 5.13 & $3.56-7.38$ \\
\hline frg4 & & & 4.18 & $3.09-5.65$ & 4.32 & $3.17-5.87$ \\
\hline frg5 & & & 3.70 & $2.69-5.10$ & 3.95 & $2.85-5.48$ \\
\hline frg 6 & & & 2.24 & $1.69-3.26$ & 2.42 & $1.73-3.38$ \\
\hline frg8 & & & \multicolumn{2}{|c|}{ NS } & 3.30 & $1.80-6.07$ \\
\hline frg7 & & & & & 1.48 & $1.04-2.09$ \\
\hline visn1 & & & & & 0.20 & $0.09-0.43$ \\
\hline visn4 & & & & & 0.41 & $0.24-0.71$ \\
\hline visn6 & & & & & 1.60 & $1.07-2.40$ \\
\hline visn8 & & & & & 1.98 & $1.37-2.86$ \\
\hline visn9 & & & & & 2.40 & $1.64-3.51$ \\
\hline visn 10 & & & & & 0.29 & $0.13-0.62$ \\
\hline visn16 & & & & & 1.45 & $1.05-2.00$ \\
\hline visn17 & & & & & 1.68 & $1.03-2.74$ \\
\hline visn20 & & & & & 2.30 & $0.17-0.51$ \\
\hline visn21 & & & & & 0.47 & $0.26-0.84$ \\
\hline visn22 & & & & & 1.54 & $1.04-2.26$ \\
\hline
\end{tabular}

Abbreviations: $\mathrm{Cl}$, confidence interval; NS, not significant; OR, odds ratio.

show those areas that were still significantly different from the national mean in our multivariate regressions, which adjusted for demographics and disability severity (research question 2). In general, the shaded areas suggest the northeast VISNs tended to provide fewer devices than the northwest and southeast VISNs. Not only were the regional differences in device provision statistically significant, many of them were proportionately large and therefore clinically significant. For example, the rate of standard manual wheelchairs provided per 100 veterans ranged from $5.1 \%$ to $28.1 \%$ across VISNs (see table 2). The relationship (unadjusted) between the provision of standard manual and hemi and lightweight rehabilitation wheelchairs was reciprocal for 4 VISNs-that is, 4 VISNs provided significantly fewer low-quality standard or depot manual wheelchairs but provided significantly more betterquality lightweight manual rehabilitation wheelchairs.

The multivariate analyses examine to what extent these differences in device provision may be accounted for by VHA administration region, demographic, or clinical characteristics.

For most device categories, adjusting for demographics and severity of disability decreased the number of VISNs whose provision was significantly different from the national mean, but it did not eliminate all VHA regional differences. For example, for beds and walkers, canes, and crutches, prior to adjusting, there were 14 VISNS with provision patterns that were significantly different than the referent VISN (data not shown; available on request from authors), but after adjusting for demographics and severity of disability, there remained 2 VISNs that were significantly different. The device with the greatest VHA regional variation, and that was least explained by controlling for severity of disability and demographics, was wheelchairs, particularly standard manual wheelchairs. After adjusting for covariates, statistically significant differences were present in 5 VISNs for low-cost wheelchairs and 11 VISNs for standard manual/depot wheelchairs (see fig 3). Significant results from the sequential logistic regression models for standard manual/depot wheelchair are shown in table 3 .

Table 3 shows that a model predicting provision of a standard manual wheelchair with only demographic variables (model 1) had a $c$ statistic of .62 and a pseudo $R^{2}$ of $2.5 \%$, which indicates that the model is only $12 \%$ better than chance and that it accounts for little more than $2 \%$ of the variability in device provision. Adding disability severity to the model (model 2) increased the $c$ statistic to .67 , and the pseudo $R^{2}$ increased to $6.2 \%$. The odds ratios for the various demographic characteristics did not change substantively with the addition of disability severity; but for rehabilitation, the odds ratio changed from 2.01 to 1.28 . This indicates that disability severity accounts for nearly half of the relationship between receiving inpatient rehabilitation and receiving a manual wheelchair. Adding VISN into the model (model 3) increased the $c$ statistic to .72 , and it further increased the pseudo $R^{2}$ to $9.8 \%$. Thus, the sequential regression models show that patient-related factors (diagnosis, demographics, severity of disability) accounted for 
Table 4: Confusion Tables Showing the Predicted Versus Actual Device Provision for the Sequential Models at Probability Equal to .22

\begin{tabular}{|c|c|c|c|c|c|c|c|}
\hline & \multicolumn{3}{|c|}{ Device Provision } & \multirow[b]{3}{*}{ Sensitivity } & \multirow[b]{3}{*}{ Specificity } & & \\
\hline & \multirow[b]{2}{*}{ Actual } & \multicolumn{2}{|c|}{ Predicted } & & & \multicolumn{2}{|c|}{ Predicted Value } \\
\hline & & Yes & No & & & Positive & Negative \\
\hline \multirow[t]{2}{*}{ Model 1} & Yes & 545 & 1518 & .26 & .67 & .12 & .85 \\
\hline & No & 4103 & 8512 & & & & \\
\hline \multirow[t]{2}{*}{ Model 2} & Yes & 905 & 315 & .74 & .52 & .31 & .09 \\
\hline & No & 2046 & 2223 & & & & \\
\hline \multirow[t]{2}{*}{ Model 3} & Yes & 886 & 334 & .73 & .60 & .34 & .88 \\
\hline & No & 1720 & 2549 & & & & \\
\hline
\end{tabular}

NOTE. Model 1, only demographic predictors. Model 2, demographic + severity of disability predictors. Model 3, demographic + severity of disability + region predictors.

only $6.2 \%$ of the variation in provision of assistive devices, and adding VHA administrative region improved the performance of the model to an extent equal to severity of disability.

Collinearity implies a lack of independence between regressors and can lead to biased estimates with inflated errors. Using the SAS "PROC REG" options for examining collinearity $(\mathrm{COLLIN}=$ collinearity diagnostics, $\mathrm{VIF}=$ Variance Inflation Factor, TOL =tolerance), we found collinearity not to be a cause for concern. ${ }^{29}$ Model 3, when used to classify patients as receiving or not receiving a device, has the following performance: sensitivity equal to .73 , specificity equal to .60 , positive predictive value equal to .34 , and negative predictive value equal to .88. Table 4 presents these values for models 1 and 2 , as well as the predicted versus actual number of veterans who were provided assistive devices.

\section{DISCUSSION}

The provision of assistive devices should be based on the patient's health needs. That makes good clinical sense and good policy. We found over 5-fold differences across the VHA in provision of manual wheelchairs, and the variability was present for diverse types of assistive devices. Wolff et al ${ }^{10}$ found similar geographic variation in mobility-related devices provided to Medicare beneficiaries. Beneficiaries residing in the South were 4 times as likely as those in the Midwest to acquire a power wheelchair. Such dramatic variation in health care is important from both a clinical and policy perspective. ${ }^{30}$ What, then, might account for this variation in provision of assistive devices? The extent of the variation in wheelchair provision in this population, which was limited to veterans with new-onset stroke, was similar to that seen for wheelchairs in our prior study, which included multiple diagnoses. ${ }^{31,32}$ Thus, diagnosis per se does not account for the wide variations assistive device provision. Nor were we able to account for much of the variation in device delivery by VHA administrative region or patient-level factors such as demographic characteristics or severity of disability. Other possibilities include system-level factors such as device-related factors, small area variations in the skills of the providers or the skills of the providers ${ }^{1,33-36}$ or facility policies and procedures, ${ }^{33}$ and/or community level environmental or socioeconomic factors.

Our data suggest that an underlying cause of the variability may be device-related. The geographic variations for beds and patient lifts were similar to one another and differed from those for the mobility-related devices. We saw inverse relationships between low-cost manual wheelchairs compared with hemi/ lightweight manual wheelchairs. One possibility that might account for this inverse relationship is regional differences in the importance clinical leaders and policy-makers place on research showing that ultralight manual wheelchairs may be more durable than standard manual wheelchairs. ${ }^{37}$ Ultralight manual wheelchairs tended to be provided to veterans with most severe disabilities (FRG 1). Clinical leaders and policy-makers may differentially influence local practices for providing lighter-weight wheelchairs to decrease caregiver burden or to prevent secondary complications from manual wheelchair propulsion seen in full-time wheelchair users. ${ }^{38,39}$

Another possibility relates to the providers involved in the prescription process. Our findings are consistent with those of Ashton et al, ${ }^{40}$ who found significant geographic variations in care provided by VHA facilities - variation that they attributed to regional differences in physicians' opinion of the best approach to health care. Recent investigators have found variations in health care delivery related to differences among providers in their propensity to intervene in gray areas of decision-making, with physicians in high-spending regions seeing patients back more frequently and recommending screening tests of unproven benefit and discretionary interventions more often than physicians in low-spending regions. ${ }^{41}$ Others have found physician specialty to be an important predictor of prescription practices. ${ }^{42}$ Sung et $\mathrm{al}^{43}$ found that uses of surgery versus medication to treat benign prostatic hypertrophy varied inversely with one another across geographic areas - a finding very similar to ours for standard manual wheelchair versus hemi and lightweight wheelchairs. Within the VHA, both primary care providers and rehabilitation therapists can prescribe diverse assistive devices. For most primary care providers, training during medical school and residency in prescription of assistive technology has been quite limited. ${ }^{44}$ To the extent that availability of rehabilitation therapists differs across VA facilities, ${ }^{45}$ site-specific differences in therapist availability could affect the frequency with which particular devices are provided.

Another important possibility that warrants further investigation is the role of the physical environment and/or regional differences in community-level socioeconomic factors. There are important differences in the physical environment across the United States that may well affect use of assistive devices-notably, weather in Northern versus Southern regions, the built environment in rural versus urban areas, and housing attributes. Neighborhood environment can affect physical activity among persons with spinal cord injury. ${ }^{46} \mathrm{We}$ also know that the home environment can be particularly problematic for stroke survivors who use wheelchairs. ${ }^{47}$ One recent study showed that communitylevel socioeconomic factors such as labor force participation and per capital gross domestic product predict independence in ADLs at the individual level, perhaps by affecting caregiver availability or support, which in turn would affect the need for particular types of assistive technology. ${ }^{48}$ We know of no studies examining the impact of environmental and community-level factors on assistive technology provision.

Our findings differ from prior studies that found significant relationships between demographic factors and use of assistive devices. $^{49-54}$ In part, this may be a result of our focus on provision as opposed to use, but more likely, it is a result of controlling for disability severity and VHA administrative region. Our initial model showed that demographic characteristics were correlated with device provision, but that relationship was no longer significant once disability severity and VISN were added to the model. Although it is reassuring that demographic characteristics do not determine device provision, the amount of variation accounted for by disability severity was equivalent to the amount of variation accounted for by VHA administrative region, and we believe that need caused by 
physical disability should be the primary driver of device prescription.

\section{Limitations and Future Research}

The associated pseudo $R^{2}$ value of our statistical model is only $9.8 \%$, suggesting that demographic and clinical characteristics and VHA administrative region are only modestly successful at discriminating between those who did and did not receive a standard wheelchair. Although we controlled for VISN, these are VHA administrative regions, and they cut across geographic characteristics such as urbanicity, terrain, and weather that could affect device provision. The administrative data did not allow us to control for social circumstances such as housing or caregiver availability. We did not examine site-specific factors like rehabilitation staffing. We did not distinguish between walkers and canes, and neither did we examine specific types of devices used for self-care. There may be important differences in use among subcategories of these devices-for example, trade-offs in use of walkers versus canes, or variability in coprescription of bathroom devices such as raised toilet seats and bathtub benches.

This was a cross-sectional study during FY-01 and FY-02, which limits attribution of causality to the relationships we found. In addition, provision patterns in fiscal years 2001 and 2002 may not represent provision patterns in 2008. The population was veterans and $96 \%$ male, limiting generalization to the nonveteran population. Last, only device provision was measured, and we do not know the extent to which the prescribed devices were actually used. While the limitations in the study are substantive, they serve to point the direction for future research to help understand the very high variability our study showed in provision of assistive technology to veterans with comparable levels of physical disability poststroke.

\section{CONCLUSIONS}

Our research identified substantive variation in the provision of assistive devices to veterans poststroke, and we found that neither demographic/clinical characteristics nor VHA administrative region accounted adequately for the variation. The VHA is a national health care system and, theoretically, veterans should have equal access to assistive devices regardless of where they live. Ensuring equal access will require directed research to improve the evidence base for assistive technology prescription and practices. It also will require policies and clinical education that consider ongoing technological advances, the increasing diversity in the devices themselves, and the breadth of personnel involved in assistive technology delivery. ${ }^{33}$

\section{References}

1. Ashton CM, Petersen NJ, Souchek J, et al. Geographic variations in utilization rates in veterans affairs hospitals and clinics. N Engl J Med 1999;340:32-9.

2. Detsky AS, Regional variation in medical care. N Engl J Med 1995;333:589-90.

3. Jha AK, Wright SM, Perlin JB. Performance measures, vaccinations, and pneumonia rates among high-risk patients in Veterans Administration health care. Am J Public Health 2007;97:2167-72.

4. Invacare. Veranda. Available at: http://www.invacare.com/ cgi-bin/imhqprd/inv_catalog/prod_cat.jsp?s $=0 \&$ startInd $=10 \&$ catOID $=-536885347$. Accessed May 26, 2008.

5. Invacare. Crossfire titanium. Available at: http://www. invacare.com/cgi-bin/imhqprd/inv_catalog/prod_cat.jsp?s=0\&cat $\mathrm{OID}=-536885354$. Accessed May 26, 2008.

6. Permobile. X850 corpus. Available at: http://www.permobilusa.com/ USA/Products/Rehab/X850-Corpus/. Accessed November 17, 2009.
7. Office of the Inspector General. New efforts aimed at stopping abuse of the power wheelchair benefit in the Medicare program. OIG-HHS. August 8, 2008. Available at: http://www.oig.hhs.gov/ publications/docs/press/2003/090903release.pdf. Accessed November 17, 2009.

8. Hubbard SL, Fitzgerald SG, Reker DM, Boninger ML, Cooper RA. Demographic characteristics of veterans receiving wheelchairs and scooters from the Veterans Health Administration. J Rehabil Res Dev 2006;43:831-44.

9. Hubbard SL, Fitzgerald SG, Vogel WB, Reker DM, Cooper RA, Boninger ML. Distribution and cost of wheel chairs and scooters provided by Veterans Health Administration. J Rehabil Res Dev 2007;44:581-92.

10. Wolff JL, Agree EM, Kasper JD. Wheelchairs, walkers, and canes: what does Medicare pay for, and who benefits? Health Aff (Millwood) 2005;24:1140-9.

11. Ambrosio F, Boninger ML, Fitzgerald SG, Hubbard SL, Schwid S, Cooper RA. Comparison of mobility device delivery within Department of Veterans Affairs for individuals with multiple sclerosis versus spinal cord injury. J Rehabil Res Dev 2007;44: 693-702.

12. Lawrence ES, Coshall C, Dundas R, et al. Estimates of the prevalence of acute stroke impairments and disability in a multiethnic population. Stroke 2001;32:1279-84.

13. Jones MR, Horner RD, Edwards LJ, et al. Racial variation in initial stroke severity. Stroke 2000;31:563-7.

14. Duncan PW, Reker DM, Kwon S, et al. Measuring stroke impact with the stroke impact scale: telephone versus mail administration in veterans with stroke. Med Care 2005;43:507-15.

15. UDSMR. The FIM system. 2002. Available at: http://www. udsmr.org/. Accessed November 17, 2009.

16. VIReC. VA Resource Information Center. Available at: http:// www.virec.research.va.gov/index.htm. Accessed March 27, 2008.

17. Reker DM, Hamilton BB, Duncan RW, Yeh SC, Rosen A. Stroke: who's counting what? J Rehabil Res Dev 2002;39:vii

18. Gignac MA, Cott C, Badley EM. Adaptation to disability: applying selective optimization with compensation to the behaviors of older adults with asteoarthritis. Psychol Aging 2002;17:520-4.

19. Fuhrer MJ, Jutai JW, Schearer MJ, DeRuyter F. A framework for the conceptual modeling of assistive technology device outcomes. Disabil Rehabil 2003:25:1243-51.

20. Jutai JW, Fuhrer MJ, Demers L, Scherer MJ, DeRuyter F. Toward a taxonomy of assistive technology device outcomes. Am J Phys Med Rehabil 2005;84:294-302.

21. Gosman-Hedstrom G, Claesson L, Blomstrand C, Fagerberg B. Use and cost of assistive technology the first year after stroke. Int J Technol Assess Health Care 2002;18:520-7.

22. United States Government. Assistive Technology Act of 1998. 1998. Available at: http://www.section508.gov/docs/AT1998.html. Accessed October 23, 2002.

23. Vogel WB, Berlowitz DR, Hoenig D, et al. Function-based risk adjustment in statistical models: systems vs. components. In HSR\&D National Meeting: managing recovery and health through the continium of care. Washington (DC):2007. http://www.hsrd. research.va.gov/meetings/2007/display_abstract.cfm?RecordID = 234. Accessed: February 16, 2010.

24. Granger C. Quality and outcome measures for rehabilitation programs. e-Medicine. 2007. Available at: http://www.emedicine. com/pmr/topic155.htm. Accessed December 26, 2007.

25. Stineman MG, Escarce JJ, Goin JE, Hamilton BB, Granger CV, Williams SV. A case-mix classification system for medical rehabilitation. Med Care 1994;32:366-79.

26. Stineman MG, Tassoni CJ, Escarce JJ, et al. Development of function-related groups version 2.0: a classification system for medical rehabilitation. Health Serv Res 1997;32:529-48. 
27. Hochberg Y. A sharper Bonferroni procedure for multiple tests of significance. Biometrika 1988;75:800-2.

28. Biddiss EA, Chau TT. Multivariate prediction of upper limb prosthesis acceptance or rejection. Disabil Rehabil 2008;3:181-92.

29. Allison PD. Logistic regression using the SAS system: theory and application. 4th ed. Cary: SAS Publishing; 1999.

30. Baicker KA, Chandra A, Skinner JS. Geographic variation in health care and the problem of measuring racial disparities. Perspect Biol Med 2005;48(1 Suppl):S42-53.

31. Hubbard SL, Fitzgerald SG, Reker DM, Boninger ML, Cooper RA, Kazis LE. Demographic characteristics of veterans receiving wheelchairs and scooters from the Veterans Health Administration. J Rehabil Res Dev 2006:43:831-43.

32. Hubbard SL, Fitzgerald SG, Vogel B, Reker DM, Cooper RA, Boninger ML. Distribution and cost of wheelchairs and scooters provided by the Veterans Health Administration. J Rehabil Res Dev 2007;44:581-92.

33. Eggers SL, Myaskovsky L, Burkitt KH, et al. A preliminary model of wheelchair service delivery. Arch Phys Med Rehabil 2009;90: 1030-8.

34. Wennberg J, Gittlelsohn A. Variations in medical care among small areas. Sci Am 1982;246:120-34.

35. Wennberg JE, Understanding geographic variations in health care delivery. N Engl J Med 1999;340:52-3.

36. Wennberg JE. Practice variation and health care reform: connection the dots. Health Aff (Millwood) 2004. Suppl Web Exclusives: VAR140-4.

37. Fitzgerald SG, Cooper RA, Boninger ML, Rentschler AJ. Comparison of fatigue life for three types of manual wheelchairs. Arch Phys Med Rehabil 2001;82:1484-8.

38. Mercer JL, Boninger ML, Koontz AM, Ren D, Dyson-Hudson T, Cooper R. Shoulder joint kinetics and pathology in manual wheelchair users. Clin Biomech 2006;21:781-9.

39. vanDrogelen S, Boninger ML, Impink BG, Khalaf T. Ultrasound imaging of acute biceps tendon chnges after wheelchair sports. Arch Phys Med Rehabil 2007;88:381-5.

40. Ashton CM, Perersen NJ, Souchek J, et al. Geographic variations in utilization rates in veterans affairs hospitals and clinics. N Engl J Med 1999;340:32-9.

41. Sirovich B, Gallagher PM, Wennberg DE, Fischer ES. Discretionary decision making by primary care physicians and the cost of U.S. health care. Health Aff (Millwood) 2008;27:813-23.
42. Steinman MA. Predictors of broad-spectrum antibiotic prescribing for acute respiratory tract infections in adult primary care. JAMA 2003; $12: 719-25$.

43. Sung JC, Curtis LH, Schulman KA, Albala DM. Geographic variations in the use of medical and surgical therapies for benign prostatic hyperplasia. J Urol 2006;175(3 Pt 1):1023-7.

44. Hoenig H, Mayer-Oakes A, Siebens H, Fink A, Brummel-Smith K, Rubenstein LV. Geriatric rehabilitation: what do physicians know about it and how should they use it? Am Geriatric Soc 1994:42:341-7.

45. Hoenig H, Sloane R, Homer R, Zolkewitz M, Reker DM. Differences in rehabilitation services and outcomes among stroke patients cared for in Veterans Hospitals. Health Ser Res 2001;35: 1293-318.

46. Liang H, Tomey K, Chen D, Savar NL, Rimmer JH, Braunschweig CL. Objective measures of neighborhood environment and self-reported physical activity in spinal cord injured men. Arch Phys Med Rehabil 2008;89:1468-73.

47. Reid D. Accessibility and usability of the physical housing environment of seniors with stroke. Int J Rehabil Res 2004;27:203-8.

48. Yi A, Gu C, Purser J, Liu Y, Hoenig H, Christakis N. Effects of environmental factors on elderl health and survival in China. Am J Public Health. In press.

49. NCHS. Trends and differential use of assistive technology devices. Washington (DC): National Center for Health Statistics; 1994.

50. Tomita M, Mann W, Fraas L, Burns L. Racial differences of frail elders in assistive technology. Assist Technol 1997;9:140-51

51. Zimmer Z, Chappell N. Mobility restriction and the use of devices among seniors. J Aging Health 1994;6:185-208.

52. Rubin R, White-Means S. Race, disability and assistive devices: sociodemographics or discrimination. Int J Soc Econ 2001;28: 927-41.

53. Kaye H, Kang T, Laplante M. Mobility device use in the U.S. Washington (DC): US Department of Education, National Institute of Disability and Rehabilitation Research: 2000.

54. Hunt PC, Boninger ML, Cooper RA, Zafonte RD, Fitzgerald SG, Schmeler MR. Demographic and socioeconimic factors associated with disparity in wheelchair customizability among individuals with traumatic spinal cord injury. Arch Phys Med Rehabil 2004; $85: 1859-64$.

\section{Supplier}

a. SAS Inc, 180 N Stetson Ave, \#1600, Chicago, IL 60601. 


\section{Average ADL Devices per Patient by VISN}

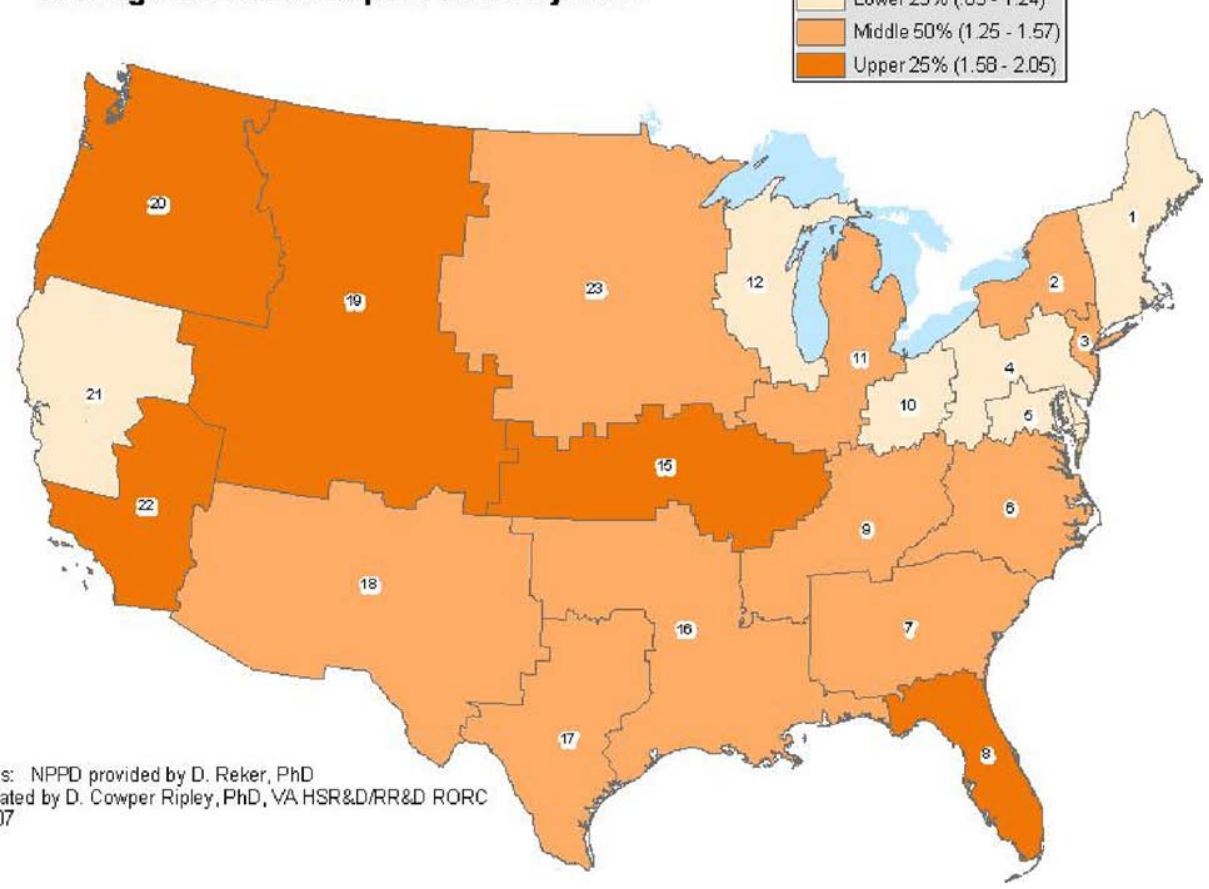

Supplemental Fig 3. Shading indicates use patterns by quartile, per VISN, per device. Light shading, $0 \%$ to $25 \%$ quartile; medium shading $25 \%$ to $75 \%$ quartiles; dark shading, $75 \%$ to $100 \%$ quartile. 